\title{
Lipid Changes in Mature-green Tomatoes during Ripening, during Chilling, and after Rewarming subsequent to Chilling
}

\author{
Bruce D. Whitaker \\ Horticultural Crops Quality Laboratory, Beltsville Agricultural Research Center, Agricultural Research \\ Service, U.S. Department of Agriculture, Beltsville, MD 20705-2350
}

Additional index words. Lycopersicon esculentum, steryl lipid, phospholipid, galactolipid, fatty acid, chlorophyll, carotenoid

\begin{abstract}
Lipid composition and pigment content were determined in pericarp of 'Pik Red' tomatoes (Lycopersicon esculentum Mill.) that were harvested when mature-green (MG) then ripened for 1 or 14 days at $20 \mathrm{C}$, chilled for 11 or 21 days at $2 \mathrm{C}$, or chilled for 21 days and transferred to $20 \mathrm{C}$ for 4 days (rewarmed). During ripening, chlorophyll fell below a detectable level, carotenes increased 100-fold, phospholipids (PLs) dropped $\approx 20 \%$, and galactolipids (GLs) dropped $\approx 35 \%$. Fatty-acid unsaturation decreased slightly. Steryl esters (SEs), more than free sterols (FSs) and steryl glycosides (SGs), increased at the expense of acylated steryl glycosides (ASGs), and in all four steryl lipids, the stigmasterol : sitosterol ratio rose dramatically, whereas the level of isofucosterol fell sharply. During chilling, chlorophyll declined $\approx 40 \%$ and carotenes $\approx \mathbf{6 0 \%}$. PL content did not change, whereas GL fell $\approx 15 \%$. Fatty-acid unsaturation increased slightly. FS, much more than SG and SE, increased at the expense of ASG. The stigmasterol : sitosterol ratio changed little in ASG, SG, and SE but declined in FS. Isofucosterol increased in FS and SE. Rewarming had little effect on the levels of chlorophyll, carotenes, or PL levels, but caused GL to fall another $\approx 15 \%$. Fatty-acid unsaturation decreased slightly in GL and ASG. The distribution of total sterol in ASG, SG, FS, and SE changed dramatically, yielding proportions close to those in unchilled MG fruit. Also, 4 days after rewarming, the stigmasterol : sitosterol ratio had increased sharply, particularly in FS and SE, and there was a further rise in isofucosterol in all four steryl lipids. These results indicate that chloroplast damage occurs during chilling, but PL-rich cell membranes are not degraded, even upon rewarming. Changes in sterol composition and conjugation during chilling and after rewarming could result in membrane dysfunction.
\end{abstract}

Tomatoes are prone to chilling injury $(\mathrm{CI})$ when stored at temperatures of 0 to $10 \mathrm{C}$. CI symptoms include failure to ripen properly, pitting, watersoaking, and increased postharvest decay (Morris, 1982). Dysfunction of one or more cell membranes at chilling temperature is thought to be the primary event that ultimately leads to CI (Lyons, 1973; Parkin et al., 1989). However, CI symptoms generally do not appear until after tomatoes are transferred to nonchilling temperatures (rewarmed) (Morris, 1982). Studies of electrolyte leakage and other physiological parameters (King and Ludford, 1983; Saltveit, 1991) have indicated that chilling adversely affects the plasma membrane in tomato pericarp tissue, whereas ultrastructural and biophysical studies have provided evidence that the tonoplast is also affected (Marangoni and Stanley, 1989; Marangoni et al., 1989).

Tomatoes are very susceptible to $\mathrm{CI}$ at the mature-green (MG) stage of development, and partial ripening reduces chilling sensitivity (Autio and Bramlage, 1986; McColloch et al., 1966). Ultrastructural studies of pericarp tissue from MG fruit have shown that the internal lamellae of the chloroplasts become disorganized after 7 to 10 days of chilling (Marangoni et al., 1989; Moline, 1976). It has also been reported that selective loss of monogalactosyldiacylglycerol (MGDG), the major galactolipid (GL) in chloroplasts, is associated with CI of MG tomatoes (Nguyen and Mazliak, 1990). Thus, disruption of chloroplast membranes during chilling may interfere with the transformation to chromoplasts after fruit are rewarmed (Moline, 1976).

Received for publication 29 Sept. 1993. Accepted for publication 22 Mar. 1994. I acknowledge the valuable technical assistance of Shawn Cichy. Use of a company or product name does not imply approval or recommendation of the product by the U.S. Dept. of Agriculture to the exclusion of others that may also be suitable. The cost of publishing this paper was defrayed in part by the payment of page charges. Under postal regulations, this paper therefore must be hereby marked advertisement solely to indicate this fact.
Studies comparing the effects of chilling and ripening on the lipid content of tomato pericarp have shown that loss of phospholipids (PLs) and increase in free fatty acids are relatively slight during chilling (Bergevin et al., 1993; Nguyen and Mazliak, 1990; Whitaker, 1991a). It was also found that total sterols increased during storage at ripening and chilling temperatures, but the composition and distribution of sterols in the free, esterified, and glycosylated fractions differed in partially ripened and chilled fruit after 12 days (Whitaker, 1991a). This study was undertaken to ascertain whether the lipid changes observed during chilling persist after rewarming and to determine what changes occur specifically during rewarming. The objective was to identify changes in lipid metabolism induced by chilling and/or rewarming that could result in membrane dysfunction.

\section{Materials and Methods}

Plant material. 'Pik Red' tomato plants were grown in a field plot at Beltsville, Md., using standard horticultural practices. Large to medium fruit (230 $\pm 29 \mathrm{~g}$ fresh weight) were hand-harvested at the MG stage on 23 July 1992. Fruit were washed, air dried, and sorted into six groups (A, B, C, D, E, and F) of at least eight fruit, each roughly equal in size and weight. After 1 day at $20 \mathrm{C}$, colorimetry $\left(a^{*}\right)$ values were recorded for each fruit using a chromometer. Group A was processed immediately, Group B was stored 14 days at $20 \mathrm{C}$, Group $\mathrm{C}$ was stored 11 days at $2 \mathrm{C}$, Group D was stored 21 days at $2 \mathrm{C}$, Group E was stored 21 days at $2 \mathrm{C}$ then 4 days at 20C, and Group F was stored 21 days at $2 \mathrm{C}$ then 14 days at $20 \mathrm{C}$. At the end of storage, $\mathrm{a}^{*}$ values were recorded and pericarp tissue from the upper half of each fruit (minus the stem scar area) was excised, blotted, frozen in liquid $\mathrm{N}_{2}$, and stored in individual freezer bags at 80C. Extensive fungal decay of fruit in group F precluded collecting tissue samples. 
Lipid extraction, fractionation, and analysis. One 10-g sample of outer pericarp tissue from each of eight fruit within each group (A through $\mathrm{E}$ ) was frozen in liquid $\mathrm{N}_{2}$ and lyophilized overnight. The dried tissue was pulverized and extracted with $30 \mathrm{ml}$ of 2 chloroform : 1 methanol. Lipid extracts were washed, dried under an $\mathrm{N}_{2}$ stream, and redissolved in $2 \mathrm{ml}$ of chloroform. Aliquots were withdrawn for spectrophotometric assay of chlorophyll and total PL content (Whitaker, 1991b). Total lipids were separated into neutral, glyco-, and phospholipid fractions by silicic acid column chromatography, and individual lipid classes were isolated using silica solid-phase extraction cartridges or thin-layer chromatography (Whitaker, 1988, 1991b). Carotenes and lycopene in the neutral lipid fraction were dissolved in hexane and quantified spectrophotometrically (Davies, 1976). Fatty-acid methyl esters (FAMEs) were produced by incubating acyl lipids with $14 \%$ boron trifluoride or $0.6 \mathrm{~m} \mathrm{KOH}$ in methanol. Free sterols (FSs) and sterols derived from steryl esters (SEs), acylated steryl glycosides (ASGs), and steryl glycosides (SGs) were isolated by precipitation with digitonin (Whitaker, 1988). FAMEs and sterols were analyzed and quantified by gas-liquid chromatography with flame-ionization detection (Whitaker, 1992a; Whitaker and Lusby, 1989). The GLs-MGDG and digalactosyl-diacylglycerol (DGDG), ASGs, SGs, and individual PLs [phosphatidylcholine (PC), phosphatidylethanolamine (PE), phosphatidic acid (PA), phosphatidyl-glycerol (PG), phosphatidylinositol (PI), and lysophosphatidylcholine (LPC)] were quantified using various spectrophotometric assays as previously described (Whitaker, 1991b, 1992a).
Data handling and statistical analysis. For each lipid class, moiety, or ratio, the data from six or eight samples from separate fruit were used to calculate the mean value $\pm \mathrm{SD}$. The least significant difference between treatments at $P=0.05\left(\mathrm{LSD}_{0.05}\right)$ was then determined by an analysis of variance followed by Student's $t$ test.

\section{Results}

The colorimetry a* value, a measure of redness to greenness, was used as an index of fruit color (Table 1). Values ranged from about -15 for $\mathrm{MG}$ fruit to $\approx 35$ for red-ripe. After 1 day at $20 \mathrm{C}$ or 11 or 21 days of chilling at $2 \mathrm{C}$, fruit remained at the $\mathrm{MG}$ stage. The small increase in $\mathrm{a}^{*}$ in fruit stored 21 days at $2 \mathrm{C}$ (Group D) probably reflected the partial loss of chlorophyll (Table 2), whereas inspection of the locular tissues in fruit from Group $\mathrm{E}$ ( 21 days at $2 \mathrm{C}+4$ days at 20C) indicated fruit to be at the breaker stage. After 14 days at 20C, Group B fruit were fully ripened, but when the 14 days at 20C were preceded by 21 days of chilling (Group F), ripening had progressed only to the pink stage and the stem scar region of the fruit was extensively decayed.

The total PL content declined $>20 \%$ with ripening (14 days at 20C) but did not change appreciably during chilling or after 21 days at 2C followed by rewarming and 4 days at 20C (Table 2). Total GL content and the MGDG : DGDG ratio declined much more with ripening than with 21 days of chilling. However, during 4 days at 20C after 21 days at 2C, total GL content and the MGDG : DGDG ratio decreased. Chlorophyll content decreased slightly

Table 1. Hunter colorimeter $\left(\mathrm{a}^{*}\right)$ values of tomatoes before and after storage. ${ }^{\mathrm{z}}$

\begin{tabular}{|c|c|c|c|c|}
\hline Group & Storage regime & Initial $\mathrm{a}^{*}$ value $^{\mathrm{y}}$ & Final a* value & $\begin{array}{l}\text { Ripening stage } \\
\text { after storage }\end{array}$ \\
\hline$\overline{\mathrm{A}}$ & 1 Day at $20 \mathrm{C}$ & $-15.7 \pm 1.1 \mathrm{a}$ & $-15.7 \pm 1.1 \mathrm{a}$ & Mature green \\
\hline B & 14 Days at $20 \mathrm{C}$ & $-14.5 \pm 1.2 \mathrm{a}$ & $35.6 \pm 2.1 \mathrm{~d}$ & Red ripe \\
\hline $\mathrm{C}$ & 11 Days at $2 \mathrm{C}$ & $-14.9 \pm 0.9 \mathrm{a}$ & $-14.6 \pm 0.8 \mathrm{ab}$ & Mature green \\
\hline $\mathrm{D}$ & 21 Days at $2 \mathrm{C}$ & $-15.0 \pm 1.5 \mathrm{a}$ & $-12.4 \pm 0.9 \mathrm{ab}$ & Mature green \\
\hline $\mathrm{E}$ & 21 Days at $2 \mathrm{C}+4$ Days at $20 \mathrm{C}$ & $-14.6 \pm 1.0 \mathrm{a}$ & $-10.9 \pm 1.5 b$ & Breaker \\
\hline $\mathrm{F}$ & 21 Days at $2 \mathrm{C}+14$ Days at $20 \mathrm{C}$ & $-14.7 \pm 1.0 \mathrm{a}$ & $25.9 \pm 7.7 \mathrm{c}$ & Pink-orange $^{\mathrm{x}}$ \\
\hline
\end{tabular}

${ }^{\mathrm{z} V}$ alues indicate the mean \pm SD of three readings from the equatorial region of each of eight fruit.

yean separation within columns at $P<0.05$.

${ }^{\mathrm{x}}$ Extensive fungal decay in the stem scar region of all fruit.

Table 2. Glycerolipid and pigment content of pericarp tissue after storing mature-green tomatoes for 1 or 14 days at $20 \mathrm{C}, 11$ or 21 days at $2 \mathrm{C}$, or 21 days at $2 \mathrm{C}$ then 4 days at $20 \mathrm{C}$. $^{\mathrm{z}}$

\begin{tabular}{|c|c|c|c|c|c|}
\hline \multirow[b]{2}{*}{ Lipid or pigment ${ }^{\mathrm{y}}$} & \multicolumn{5}{|c|}{ Storage regime } \\
\hline & 1 Day 20C & 14 Days 20C & 11 Days 2C & 21 Days 2C & $\begin{array}{l}21 \text { Days } 2 \mathrm{C} \\
+4 \text { Days } 20 \mathrm{C}\end{array}$ \\
\hline \multicolumn{6}{|l|}{ Glycerolipid } \\
\hline Total PL ${ }^{\mathrm{y}}$ & $366 \pm 33 \mathrm{a}^{\mathrm{x}}$ & $282 \pm 15 b$ & $361 \pm 20 a$ & $357 \pm 24 \mathrm{a}$ & $370 \pm 18 \mathrm{a}$ \\
\hline MGDG & $86 \pm 4 \mathrm{a}$ & $48 \pm 9 c$ & $77 \pm 4 \mathrm{ab}$ & $70 \pm 13 b$ & $57 \pm 16 b c$ \\
\hline DGDG & $46 \pm 4 \mathrm{a}$ & $35 \pm 7 b$ & $39 \pm 6 a b$ & $41 \pm 7 \mathrm{ab}$ & $36 \pm 5 b$ \\
\hline Total GL (MGDG + DGDG) & $132 \pm 7 \mathrm{a}$ & $83 \pm 13 c$ & $116 \pm 8 \mathrm{a}$ & $111 \pm 17 \mathrm{ab}$ & $93 \pm 19 b c$ \\
\hline \multicolumn{6}{|l|}{ Pigments } \\
\hline Chlorophyll & $24 \pm 4 \mathrm{a}$ & $\mathrm{ND}^{\mathrm{w}}$ & $21 \pm 3 \mathrm{ab}$ & $14 \pm 3 b$ & $14 \pm 3 b$ \\
\hline Carotenes (nonpolar) & $0.5 \pm 0.2 b$ & $51 \pm 18 \mathrm{a}$ & $0.2 \pm 0.2 \mathrm{c}$ & $0.2 \pm 0.2 \mathrm{c}$ & $0.2 \pm 0.2 \mathrm{c}$ \\
\hline \multicolumn{6}{|l|}{ Lipid ratios } \\
\hline GL : PL & $0.36 \mathrm{a}$ & $0.29 \mathrm{bc}$ & $0.32 \mathrm{ab}$ & $0.31 \mathrm{~b}$ & $0.25 \mathrm{c}$ \\
\hline MGDG : DGDG & $1.87 \mathrm{a}$ & $1.37 \mathrm{c}$ & $1.97 \mathrm{a}$ & $1.70 \mathrm{~b}$ & $1.58 \mathrm{~b}$ \\
\hline
\end{tabular}

${ }^{\mathrm{z}}$ Values (nmol glycerolipid or $\mu \mathrm{g}$ pigment per $\mathrm{g}$ fresh weight) indicate the mean $\pm \mathrm{sD}$ from six fruit.

yPL = phospholipid, MGDG = monogalactosyldiacylglycerol, DGDG = digalactosyldiacylglycerol, GL = galactolipid.

${ }^{x}$ Mean separation within rows at $P<0.05$.

${ }^{\mathrm{w}} \mathrm{ND}=$ not detected. 
over 11 days at $2 \mathrm{C}$ and had fallen $>40 \%$ after 21 days at $2 \mathrm{C}$, with no further decrease over 4 days at 20C after rewarming. Chlorophyll was not detected in the fully ripened fruit (14 days at 20C). The level of nonpolar carotenes (carotenes and lycopene) increased 100-fold during 14 days of ripening at 20C. In contrast, during storage at $2 \mathrm{C}$, carotene levels fell below those at 1 day postharvest, and there was no increase 4 days after rewarming 21day-chilled fruit.

Changes in PL composition during storage were generally minor (Table 3). With ripening, a decline in PC plus PE was offset by a near doubling of PA and small increases in PI and LPC; the PC : PE ratio also increased slightly. Changes during chilling were similar-a decrease in PC plus PE with increases in PA, PI, and
LPC, but the PA increase was much smaller than that during ripening and there was no change in the $\mathrm{PC}: \mathrm{PE}$ ratio. The PL composition of fruit chilled for 21 days had changed very little 4 days after rewarming.

The fatty-acid compositions of PL, GL, and ASG from MG fruit held 1 day at 20C (Table 4) are typical for these acyl lipids. Linoleate (18:2) and palmitate (16:0) are predominant in PL. Linolenate (18:3) is the major fatty acid in GL, with 16:0 much lower in MGDG than in DGDG, and the composition of ASG is highly saturated $(\approx 75 \% 16: 0+18: 0+20: 0)$. As shown in Table 5, the unsaturation index (UI) [mol percent $18: 1+2 \times$ mol percent $18: 2+3 \times$ mol percent $18: 3) \div 100$ ] of these acyl lipids generally changed very little during storage, regardless of the temperature

Table 3. Phospholipid composition of pericarp tissue after storing mature-green tomatoes for 1 or 14 days at $20 \mathrm{C}, 11$ or 21 days at $2 \mathrm{C}$, or 21 days at $2 \mathrm{C}$ then 4 days at $20 \mathrm{C}{ }^{\mathrm{z}}$

\begin{tabular}{|c|c|c|c|c|c|}
\hline \multirow[b]{2}{*}{ Phospholipid $^{\mathrm{y}}$} & \multicolumn{5}{|c|}{ Storage regime } \\
\hline & 1 Day 20C & 14 Days 20C & 11 Days 2C & 21 Days 2C & $\begin{array}{c}21 \text { Days } 2 \mathrm{C} \\
+4 \text { Days } 20 \mathrm{C}\end{array}$ \\
\hline$\overline{\mathrm{PC}}$ & $51.2 \pm 1.8 \mathrm{a}^{\mathrm{x}}$ & $48.8 \pm 2.0 \mathrm{a}$ & $50.0 \pm 2.4 \mathrm{a}$ & $48.6 \pm 2.1 \mathrm{a}$ & $48.8 \pm 2.2 \mathrm{a}$ \\
\hline $\mathrm{PE}$ & $34.5 \pm 1.7 \mathrm{a}$ & $28.9 \pm 1.4 \mathrm{~b}$ & $34.3 \pm 2.2 \mathrm{a}$ & $33.1 \pm 2.1 \mathrm{a}$ & $33.1 \pm 1.9 \mathrm{a}$ \\
\hline PA & $6.4 \pm 1.2 \mathrm{~b}$ & $12.4 \pm 1.8 \mathrm{a}$ & $6.4 \pm 0.9 b$ & $7.6 \pm 1.3 \mathrm{~b}$ & $7.1 \pm 1.1 \mathrm{~b}$ \\
\hline PI & $5.0 \pm 1.0 \mathrm{c}$ & $6.9 \pm 1.4 \mathrm{ab}$ & $5.7 \pm 1.1 \mathrm{bc}$ & $7.2 \pm 1.2 \mathrm{a}$ & $6.9 \pm 1.0 \mathrm{ab}$ \\
\hline PG & $1.8 \pm 0.3 \mathrm{a}$ & $1.1 \pm 0.2 \mathrm{~b}$ & $1.9 \pm 0.3 \mathrm{a}$ & $1.8 \pm 0.3 \mathrm{a}$ & $1.8 \pm 0.3 \mathrm{a}$ \\
\hline LPC & $1.1 \pm 0.2 \mathrm{c}$ & $1.9 \pm 0.3 \mathrm{ab}$ & $1.7 \pm 0.3 b$ & $1.7 \pm 0.3 b$ & $2.3 \pm 0.4 \mathrm{a}$ \\
\hline $\mathrm{PC}: \mathrm{PE}$ ratio & $1.48 \mathrm{~b}$ & $1.69 \mathrm{a}$ & $1.46 \mathrm{~b}$ & $1.47 \mathrm{~b}$ & $1.47 \mathrm{~b}$ \\
\hline
\end{tabular}

${ }_{\mathrm{z}}$ Values (mol percent total phospholipid) indicate the mean \pm SD of tissue samples from six fruit.

y $\mathrm{PC}=$ phosphatidylcholine, $\mathrm{PE}=$ phosphatidylethanolamine, $\mathrm{PA}=$ phosphatidic acid, $\mathrm{PI}=$ phosphatidylinositol $; \mathrm{PG}=$ phosphatidylglycerol, $\mathrm{LPC}=$ lysophosphatidylcholine.

xMean separation within rows at $P<0.05$.

Table 4. Fatty-acid composition of acyl lipids from pericarp tissue after storing mature-green tomatoes 1 day at $20 \mathrm{C}{ }^{\mathrm{z}}$

\begin{tabular}{|c|c|c|c|c|c|c|}
\hline \multirow[b]{2}{*}{ Fatty acid } & \multicolumn{3}{|c|}{ Phospholipids $^{y}$} & \multicolumn{2}{|c|}{ Galactolipids $^{x}$} & \multirow{2}{*}{$\frac{\text { Steryl lipid }^{\mathrm{w}}}{\text { ASGs }}$} \\
\hline & $\mathrm{PC}$ & $\mathrm{PE}$ & PA & MGDG & DGDG & \\
\hline $16: 0$ & 33.9 & 31.6 & 22.5 & 5.2 & 20.1 & 63.4 \\
\hline 18:0 & 4.3 & 3.6 & 4.8 & 1.1 & 5.2 & 8.3 \\
\hline $18: 1$ & 1.7 & 1.3 & 2.9 & 0.5 & 1.3 & 0.8 \\
\hline $18: 2$ & 47.5 & 51.9 & 53.9 & 19.0 & 23.1 & 17.4 \\
\hline $18: 3$ & 11.9 & 10.9 & 15.1 & 72.8 & 50.3 & 7.2 \\
\hline $20: 0$ & 0.7 & 0.7 & 0.8 & --- & --- & 2.9 \\
\hline
\end{tabular}

${ }^{\mathrm{z}}$ Values (mol percent total fatty acids) indicate the mean for tissue samples from six fruit.

yPC = phosphatidylcholine, $\mathrm{PE}=$ phosphatidylethanolamine, $\mathrm{PA}=$ phosphatidic acid.

${ }^{\mathrm{x}} \mathrm{MGDG}=$ monogalactosyldiacylglycerol, $\mathrm{DGDG}=$ digalactosyldiacylglycerol.

${ }^{\mathrm{w}} \mathrm{ASG}=$ acylated steryl glycosides.

Table 5. Unsaturation index ${ }^{\mathrm{z}}$ of fatty-acyl lipids from pericarp tissue after storing mature-green tomatoes for 1 or 14 days at $20 \mathrm{C}, 11$ or 21 days at $2 \mathrm{C}$, or 21 days at $2 \mathrm{C}$ then 4 days at $20 \mathrm{C} .^{\mathrm{y}}$

\begin{tabular}{|c|c|c|c|c|c|c|}
\hline \multirow[b]{2}{*}{ Storage regime } & \multicolumn{3}{|c|}{ Phospholipids $^{x}$} & \multicolumn{2}{|c|}{ Galactolipids $^{\mathrm{w}}$} & \multirow{2}{*}{$\frac{\text { Steryl lipid }^{\prime}}{\text { ASGs }}$} \\
\hline & $\mathrm{PC}$ & $\mathrm{PE}$ & PA & MGDG & DGDG & \\
\hline 1 Day 20C & $1.32 \mathrm{~b}^{\mathrm{u}}$ & $1.38 \mathrm{a}$ & $1.55 \mathrm{~b}$ & $2.61 \mathrm{a}$ & $1.98 \mathrm{~cd}$ & $0.57 \mathrm{c}$ \\
\hline 14 Days 20C & $1.26 \mathrm{c}$ & $1.30 \mathrm{~b}$ & $1.57 \mathrm{~b}$ & $2.28 \mathrm{c}$ & $1.93 \mathrm{~d}$ & $0.68 \mathrm{~b}$ \\
\hline 11 Days 2C & $1.40 \mathrm{a}$ & $1.41 \mathrm{a}$ & $1.63 \mathrm{ab}$ & $2.64 \mathrm{a}$ & $2.09 \mathrm{~b}$ & $0.84 \mathrm{a}$ \\
\hline 21 Days 2C & $1.37 \mathrm{ab}$ & $1.39 \mathrm{a}$ & $1.69 \mathrm{a}$ & $2.61 \mathrm{a}$ & $2.17 \mathrm{a}$ & $0.84 \mathrm{a}$ \\
\hline 21 Days $2 \mathrm{C}+4$ Days 20C & $1.38 \mathrm{ab}$ & $1.41 \mathrm{a}$ & $1.63 \mathrm{ab}$ & $2.48 \mathrm{~b}$ & $2.03 \mathrm{bc}$ & $0.68 \mathrm{~b}$ \\
\hline
\end{tabular}

${ }^{\mathrm{z}}$ Unsaturation Index $=[\mathrm{mol}$ percent $18: 1+2 \times($ mol percent $18: 2)+3 \times($ mol percent $18: 3)] \div 100$.

yValues indicate the mean for tissue samples from six fruit.

${ }^{\mathrm{y}} \mathrm{PC}=$ phosphatidylcholine, $\mathrm{PE}=$ phosphatidylethanolamine, $\mathrm{PA}=$ phosphatidic acid.

${ }^{\mathrm{x}} \mathrm{MGDG}=$ monogalactosyldiacylglycerol, DGDG = digalactosyldiacylglycerol.

${ }^{\mathrm{w}} \mathrm{ASG}$ = acylated steryl glycosides.

"Mean separation within columns at $P<0.05$. 
regime. Overall, the UI declined slightly during ripening, with MGDG showing the greatest drop and ASG showing a small increase. In contrast, the UI of acyl lipids generally increased slightly over 11 or 21 days at 2C, particularly for ASG, PA, and DGDG. Rewarming 21-day-chilled fruit decreased UI for GL and ASG but not PL.

Total steryl lipid sterols increased $\approx 10 \%$ during ripening and decreased $\approx 10 \%$ during 21 days of chilling (Table 6 ). The increase with ripening can be attributed to a 3-fold rise in SE. The distribution of sterol in the four steryl lipid classes (ASG, SG, FS, and SE) changed dramatically with ripening, during chilling, and after rewarming. After 14 days of ripening at 20C, SE, FS, and SG had increased at the expense of ASG. The decline in ASG was even greater over 11 or 21 days at $2 \mathrm{C}$, but, in contrast with the changes in ripening fruit, FS increased much more than SE in chilled fruit. After 4 days at 20C after rewarming 21-day-chilled fruit, the distribution of sterol in the steryl lipid classes was similar to that in 1 day MG fruit except for a small increase in SG offset by a decrease in FS.

As shown in Table 7, stigmasterol, sitosterol, and their metabolic precursor isofucosterol were the predominant sterols in the steryl lipids of MG fruit stored 1 day at 20C. The percentage of stigmasterol was highest in FS, intermediate in ASG and SG (which had a similar sterol composition), and lowest in SE. Table 8 shows that the stigmasterol : sitosterol ratio and the percentage of isofucosterol in the four steryl lipid classes changed dramatically with ripening. The stigmasterol : sitosterol ratio increased sharply, particularly in FS, and isofucosterol declined by $\approx 25 \%$ to

Table 6. Steryl lipid content and distribution in pericarp tissue after storing mature-green tomatoes for 1 or 14 days at $20 \mathrm{C}, 11$ or 21 days at $2 \mathrm{C}$, or 21 days at $2 \mathrm{C}$ then 4 days at $20 \mathrm{C} .^{\mathrm{z}}$

\begin{tabular}{|c|c|c|c|c|c|}
\hline \multirow[b]{2}{*}{$\begin{array}{l}\text { Content and } \\
\text { distribution }^{\mathrm{y}}\end{array}$} & \multicolumn{5}{|c|}{ Storage regime } \\
\hline & 1 Day 20C & 14 Days 20C & 11 Days 2C & 21 Days 2C & $\begin{array}{l}21 \text { Days } 2 \mathrm{C} \\
+4 \text { Days } 20 \mathrm{C}\end{array}$ \\
\hline \multicolumn{6}{|l|}{ Steryl lipid } \\
\hline ASGs & $63 \pm 2 a^{x}$ & $49 \pm 4 c$ & $41 \pm 2 d$ & $36 \pm 4 \mathrm{e}$ & $60 \pm 2 b$ \\
\hline SGs & $15 \pm 1 c$ & $22 \pm 2 \mathrm{a}$ & $19 \pm 2 \mathrm{ab}$ & $18 \pm 3 b c$ & $18 \pm 3 b c$ \\
\hline FSs & $18 \pm 2 \mathrm{~d}$ & $25 \pm 2 c$ & $35 \pm 2 \mathrm{a}$ & $31 \pm 3 b$ & $15 \pm 3 \mathrm{e}$ \\
\hline SEs & $4 \pm 1 \mathrm{bc}$ & $13 \pm 3 a$ & $6 \pm 1 b$ & $4 \pm 2 b c$ & $3 \pm 2 c$ \\
\hline Total & $100 \pm 3 a b$ & $109 \pm 6 \mathrm{a}$ & $101 \pm 3 a b$ & $89 \pm 6 c$ & $96 \pm 5 b c$ \\
\hline \multicolumn{6}{|c|}{ Mole percent total sterol } \\
\hline ASGs & $63 \mathrm{a}$ & $45 \mathrm{~b}$ & $41 \mathrm{~b}$ & $41 \mathrm{~b}$ & $63 \mathrm{a}$ \\
\hline SGs & $15 \mathrm{~b}$ & $20 a$ & $19 \mathrm{a}$ & $20 \mathrm{a}$ & $19 \mathrm{a}$ \\
\hline FSs & $18 \mathrm{c}$ & $23 \mathrm{~b}$ & $35 \mathrm{a}$ & $35 \mathrm{a}$ & $16 \mathrm{c}$ \\
\hline SEs & $4 \mathrm{bc}$ & $12 \mathrm{a}$ & $6 \mathrm{~b}$ & $4 \mathrm{bc}$ & $3 \mathrm{c}$ \\
\hline
\end{tabular}

${ }^{\mathrm{z}}$ Values (nmol steryl lipid per $\mathrm{g}$ fresh weight) indicate the mean \pm SD for samples from six fruit.

${ }^{\mathrm{y}} \mathrm{ASG}=$ acylated steryl glycosides, SGs $=$ steryl glycosides, FSs $=$ free sterols, $\mathrm{SEs}=$ steryl esters.

${ }^{\mathrm{x}}$ Mean separation within rows at $P<0.05$.

Table 7. Sterol composition of steryl lipids from pericarp tissue after storing mature-green tomatoes 1 day at 20C. ${ }^{\mathrm{z}}$

\begin{tabular}{lcccc}
\hline \hline & \multicolumn{3}{c}{ Steryl lipid $^{\mathrm{y}}$} \\
\cline { 2 - 5 } Sterol & ASGs & SGs & FSs & SEs \\
\hline Cholesterol & $4.0 \pm 0.4$ & $3.5 \pm 0.4$ & $5.1 \pm 0.4$ & $6.6 \pm 1.0$ \\
Campesterol & $6.0 \pm 0.3$ & $5.6 \pm 0.4$ & $5.6 \pm 0.3$ & $5.8 \pm 0.6$ \\
Stigmasterol & $19.4 \pm 1.4$ & $16.3 \pm 1.0$ & $31.6 \pm 1.7$ & $6.6 \pm 0.8$ \\
Sitosterol & $48.1 \pm 2.5$ & $47.0 \pm 1.6$ & $42.6 \pm 1.8$ & $53.8 \pm 3.0$ \\
Isofucosterol & $15.2 \pm 1.8$ & $18.0 \pm 1.7$ & $7.7 \pm 0.7$ & $16.4 \pm 2.7$ \\
Others & $7.3 \pm 1.5$ & $9.6 \pm 1.4$ & $7.4 \pm 1.1$ & $10.8 \pm 1.8$
\end{tabular}

${ }^{\mathrm{z}}$ Values (weight percent total sterol) indicate the mean \pm SD for tissue samples from six to eight fruit.

${ }^{\mathrm{y}} \mathrm{ASGs}=$ acylated steryl glycosides, SGs = steryl glycosides, FSs $=$ free sterols, SEs $=$ steryl esters.

Table 8. Stigmasterol : sitosterol ratio and weight percent isofucosterol in steryl lipids from pericarp tissue after storing mature-green tomatoes for 1 or 14 days at $20 \mathrm{C}, 11$ or 21 days at $2 \mathrm{C}$, or 21 days at $2 \mathrm{C}$ then 4 days at $20 \mathrm{C}$. $^{\mathrm{z}}$

\begin{tabular}{|c|c|c|c|c|c|c|c|c|}
\hline \multirow[b]{2}{*}{ Storage regime } & \multicolumn{4}{|c|}{ Stigmasterol : Sitosterol ${ }^{\mathrm{y}}$} & \multicolumn{4}{|c|}{ Isofucosterol wt (\%) } \\
\hline & ASGs & SGs & FSs & SEs & ASGs & SGs & FSs & SEs \\
\hline 1 Day 20C & $0.40 \mathrm{c}^{\mathrm{x}}$ & $0.35 \mathrm{c}$ & $0.74 \mathrm{c}$ & $0.12 \mathrm{~b}$ & $15.2 \mathrm{a}$ & $18.0 \mathrm{~b}$ & $7.7 \mathrm{~b}$ & $16.4 \mathrm{c}$ \\
\hline 14 Days 20C & $0.97 \mathrm{a}$ & $1.10 \mathrm{a}$ & $2.81 \mathrm{a}$ & $0.41 \mathrm{a}$ & $9.6 \mathrm{~b}$ & $9.0 \mathrm{c}$ & $3.4 \mathrm{c}$ & $12.6 \mathrm{~d}$ \\
\hline 11 Days 2C & $0.38 \mathrm{c}$ & $0.33 \mathrm{c}$ & $0.63 \mathrm{c}$ & $0.15 \mathrm{~b}$ & $15.2 \mathrm{a}$ & $18.0 \mathrm{~b}$ & $13.9 \mathrm{a}$ & $20.4 \mathrm{~b}$ \\
\hline 21 Days $2 \mathrm{C}$ & $0.41 \mathrm{c}$ & $0.39 \mathrm{c}$ & $0.53 \mathrm{c}$ & $0.15 \mathrm{~b}$ & $15.3 \mathrm{a}$ & $15.7 \mathrm{~b}$ & $13.5 \mathrm{a}$ & $20.6 \mathrm{~b}$ \\
\hline 21 Days $2 C+4$ Days 20C & $0.68 \mathrm{~b}$ & $0.63 \mathrm{~b}$ & $1.84 \mathrm{~b}$ & $0.39 \mathrm{a}$ & $18.4 \mathrm{a}$ & $21.4 \mathrm{a}$ & $14.7 \mathrm{a}$ & $26.7 \mathrm{a}$ \\
\hline
\end{tabular}

${ }^{\mathrm{z}}$ Values indicate the mean for tissue samples from six to eight fruit.

${ }^{\mathrm{y}} \mathrm{ASG}$ = acylated steryl glycosides, $\mathrm{SGs}=$ steryl glycosides, $\mathrm{FSs}=$ free sterols, $\mathrm{SEs}=$ steryl esters.

${ }^{\mathrm{x}}$ Mean separation within columns at $P<0.05$. 
$50 \%$. In contrast, during chilling, the stigmasterol : sitosterol ratio changed very little, and actually decreased in FS, while the weight percent isofucosterol increased $\approx 80 \%$ and $25 \%$ in FS and SE, respectively. Over 4 days at 20C after rewarming 21-day-chilled fruit, the stigmasterol : sitosterol ratio rose sharply in all steryl lipids, particularly in FS, and this coincided with a substantial increase in the percentage of isofucosterol in all steryl lipids.

\section{Discussion}

The proposed mechanism of senescence in plant tissues entails a series of catabolic steps through which PLs are degraded and free 18:2 and 18:3, produced via deacylation, are attacked by membrane-bound lipoxygenase (LOX)-yielding hydroperoxides (FAOH) (Fobel et al., 1987; Thompson, 1984). Loss of PL, an increase in the sterol : PL ratio, accumulation of $\mathrm{FA}-\mathrm{OH}$, and generation of free radicals in cell membranes are thought to destabilize the lipid bilayer, resulting in a loss of membrane function (Parkin et al., 1989; Thompson, 1984). There is evidence that these processes play a role in the ripening and senescence of tomatoes; lipid acyl hydrolase (LAH) and LOX activities have been demonstrated in microsomal membranes (Todd et al., 1990), PL content declines with ripening as PA increases (presumably via phospholipase D activity) (Whitaker, 1993a), and sterol synthesis increases (Whitaker, 1988).

In view of the loss of membrane function induced by chilling tomatoes, as evidenced by electrolyte leakage (Bergevin et al., 1993; King and Ludford, 1983), it is logical to assume that catabolic events involved in senescence are also involved in the advent of CI (Parkin et al., 1989; Thompson, 1984). It has, in fact, been shown recently that of the four enzymes involved in PL catabolism in tomato microsomes, phosphatidate phosphatase, and LOX are inhibited at chilling temperature, whereas LAH and phospholipase D are not (Todd et al., 1992). These findings support the conclusion that the accumulation of PA and free fatty acids during chilling could disrupt membrane function. However, data from previous work and the present study indicate that 1) little if any PL is lost during chilling or over 4 days after rewarming (Bergevin et al., 1993; Whitaker, 1991a, 1992b); 2) there is no increase in PA in tomato microsomes during chilling (Whitaker, 1993a); 3) much more free 18:2 and 18:3 accumulate during ripening than during chilling (Whitaker, 1991a); and 4) PL fattyacid unsaturation actually increases slightly in chilled fruit, with no change after rewarming (Bergevin et al., 1993; Whitaker, 1993a).

A body of evidence-ultrastructural (Marangoni et al., 1989; Moline, 1976) and biochemical (Bergevin et al., 1993; Nguyen and Mazliak, 1990; Whitaker, 1993)_indicates that damage to chloroplasts, possibly via altered GL metabolism, is an important element of CI in MG tomatoes, and this may also be true for cucumbers and bell peppers (Parkin and Kuo, 1989; Whitaker, 1993b). Loss of GL and a decrease in the MGDG : DGDG ratio occur with prolonged chilling, although the magnitude of these changes seems to vary with cultivar (Nguyen and Mazliak, 1990; Whitaker, 1992b). In this study it was also noted that 1) chlorophyll and carotenes declined during chilling, 2) accelerated loss of GL after rewarming coincided with a decrease in fatty-acid unsaturation, and 3) no increase in carotenes had occurred 4 days after return to 20C. Taken together, these data support the conclusion that chilling-induced disruption of chloroplast membranes inhibits or at least delays carotenogenesis and plastid transformation after rewarming.

The apparent deleterious effect of chilling on tomato chloro- plasts explains one major CI symptom-blotchy, uneven coloration-but does not explain other phenomena such as water and electrolyte leakage or cell collapse. As stated above, there is scant evidence for a role of PL catabolism in CI in tomato through the first 4 days after rewarming, although low-level degradation could be masked by de novo synthesis. Furthermore, the small changes in PL composition during chilling, noted in this and in one previous study (Whitaker, 1993a), are not likely to be the primary cause of membrane dysfunction. One possibility yet to be examined is that chilling induces extensive rearrangement of PL molecular species, which, despite the absence of a change in fatty-acid composition, could profoundly alter the physical properties of cell membranes (Parkin et al., 1989; Thompson, 1985; Todd et al., 1990).

It is also possible that the dramatic changes in sterol metabolism during chilling and after rewarming are involved in the loss of membrane function, particularly in the sterol-rich plasma membrane. In two previous studies of tomatoes, one using pericarp tissue from 'Rutgers' (Whitaker, 1991a) and the other using isolated membranes from 'Pik-Red' (Whitaker, 1993a), similar effects of chilling on sterol metabolism were observed, and these resulted in a steryl lipid profile that differed substantially from that of partially ripened fruit stored at $15 \mathrm{C}: 1$ ) the proportion of $\mathrm{FS}$ increased much more during chilling than during ripening, whereas the opposite was true for SE, and 2) the stigmasterol : sitosterol ratio increased only slightly during chilling but rose sharply with ripening, particularly in FS. These same trends were observed in this investigation, although in this work it was found that FS, and to a lesser extent $\mathrm{SG}$, increased during chilling at the expense of ASG. A major difference between this study and the previous work with 'Rutgers' was the change in total sterol content during storage. In 'Rutgers', total sterol increased in chilled and nonchilled fruit, whereas in 'Pik-Red' a relatively small increase occurred only with ripening and was due solely to the rise in SE. The new, somewhat unexpected observation from this work was the dramatic shift in sterol composition and conjugation after rewarming 21-day-chilled fruit. Four days after return to 20C, there were two major changes from the steryl lipid profile seen at the end of chilling: 1) the distribution of total sterols in ASG, SG, FS, and SE had returned to that found in MG fruit held 1 day at 20C, indicating rapid glycosylation and acylation of FS, and 2) the stigmasterol : sitosterol ratio rose sharply in all steryl lipids to values normally corresponding to the pink stage of ripening (Whitaker, 1988). This rapid shift in sterol composition may have been potentiated during chilling by the accumulation of isofucosterol, the precursor of stigmasterol. The net result of these changes was a breaker-stage fruit with the steryl lipid profile of an early MG fruit and the sterol composition of a nearly ripe fruit. Little is known about the effects of sterol conjugates, relative to FS, on the function of plant cell membranes, so the consequences of the changes with chilling and rewarming are hard to predict. Regarding changes in the stigmasterol : sitosterol ratio, a recent, elegant study has shown that the relative amounts of these two phytosterols are important determinants of the physical properties of plant PL bilayer membranes (Schuler et al., 1991). Biochemical and biophysical studies of membranes isolated from chilled and rewarmed fruit will be required to correlate the steryl lipid changes with effects on enzymatic activity, viscosity, and semipermeability.

\section{Literature Cited}

Autio, W.R. and W.J. Bramlage. 1986. Chilling sensitivity of tomato fruit in relation to ripening and senescence. J. Amer. Soc. Hort. Sci. 111:201204.

Bergevin, M., G.P. L'Heureux, J.E. Thompson, and C. Willemot. 1993. 
Effect of chilling and subsequent storage at $20^{\circ} \mathrm{C}$ on electrolyte leakage and phospholipid fatty acid composition of tomato pericarp. Physiol. Plant. 87:522-527.

Davies, B. H. 1976. Carotenes, p. 149-154. In: T.W. Goodwin (ed.). Chemistry and biochemistry of plant pigments. Academic Press, London.

Fobel, M., D.V. Lynch, and J.E. Thompsom. 1987. Membrane deterioration in senescing carnation flowers. Plant Physiol. 85:204-211.

King, M.M. and P.M. Ludford. 1983. Chilling injury and electrolyte leakage in fruit of different tomato cultivars. J. Amer. Soc. Hort. Sci. 108:74-77.

Lyons, J.M. 1973. Chilling injury in plants. Annu. Rev. Plant Physiol. 24:445-466.

Marangoni, A.G., A.K. Smith, R.Y. Yada, and D.W. Stanley. 1989. Ultrastructural changes associated with chilling injury in mature-green tomato fruit. J. Amer. Soc. Hort. Sci. 114:958-962

Marangoni, A. G. and D. W. Stanley. 1989. Phase transitions in microsomal liposomes from chilling sensitive and chilling resistant tomato plants and fruit. Phytochemistry 28:2293-2301.

McColloch, L.P., J.N. Yeatman, and P. Loyd. 1966. Color changes and chilling injury of pink tomatoes held at various temperatures. U.S. Dept. Agr. Mktg. Res. Rpt. 735.

Moline, H.E. 1976. Ultrastructural changes associated with chilling of tomato fruit. Phytopathology 66:617-624.

Morris, L.L. 1982. Chilling injury of horticultural crops: An overview. HortScience 17:161-162.

Nguyen, X.V. and P. Mazliak. 1990. Chilling injury induction is accompanied by galactolipid degradation in tomato pericarp. Plant Physiol. Biochem. 28:283-291.

Parkin, K.L. and S.J. Kuo. 1989. Chilling induced lipid degradation in cucumber (Cucumis sativus L. cv. Hybrid C) fruit. Plant Physiol. 90:1049-1056.

Parkin, K.L., A.G. Marangoni, R.L. Jackman, R.Y. Yada, and D.W. Stanley. 1989. Chilling injury. A review of possible mechanisms. J. Food Biochem. 13:127-153.

Saltveit, Jr., M.E. 1991. Prior temperature exposure affects subsequent chilling sensitivity. Physiol. Plant. 82:529-536.

Schuler, I., A. Milon, Y. Nakatani, G. Ourisson, A.M. Albrecht, P.
Benveniste, and M.A. Hartmann. 1991. Differential effects of plant sterols on water permeability and on acyl chain ordering of soybean phosphatidylcholine bilayers. Proc. Natl. Acad. Sci. USA 88:69266930.

Thompson, Jr., G.A. 1985. Mechanisms of membrane response to environmental stress, p. 347-358. In: J.B. St. John, E. Berlin, and P.C. Jackson (eds.). Frontiers of membrane research in agriculture. Rowman \& Allanheld, Totowa, N.J.

Thompson, J.E. 1984. Physical changes in the membranes of senescing and environmentally stressed plant tissues, p. 85-108. In: M. Shinitzky (ed.). Physiology of membrane fluidity. vol. 2. CRC Press, Boca Raton, Fla.

Todd, J.F., G. Paliyath, and J.E. Thompson. 1990. Characteristics of a membrane-associated lipoxygenase in tomato fruit. Plant Physiol. 94:1225-1232.

Todd, J.F., G. Paliyath, and J.E. Thompson. 1992. Effect of chilling on the activities of lipid degrading enzymes in tomato fruit microsomal membranes. Plant Physiol. Biochem. 30:517-522.

Whitaker, B.D. 1988. Changes in the steryl lipid content and composition of tomato fruit during ripening. Phytochemistry 27:3411-3416.

Whitaker, B.D. 1991a. Changes in lipids of tomato fruit stored at chilling and non-chilling temperatures. Phytochemistry 30:757-761.

Whitaker, B.D. 1991b. Growth conditions and ripening influence plastid and microsomal membrane lipid composition in bell pepper fruit. $\mathrm{J}$. Amer. Soc. Hort. Sci. 116:528-533.

Whitaker, B.D. 1992a. Glycerolipid-fatty-acid desaturase deficiencies in chloroplasts from fruits of Capsicum annuum L. Planta 187:261-265.

Whitaker, B.D. 1992b. Changes in galactolipid and phospholipid levels of tomato fruits stored at chilling and nonchilling temperatures. Phytochemistry 31:2627-2630.

Whitaker, B.D. 1993a. Lipid changes in microsomes and crude plastid fractions during storage of tomato fruits at chilling and nonchilling temperatures. Phytochemistry 32:265-271.

Whitaker, B.D. 1993b. Lipid changes in bell pepper fruit during chilling and rewarming. HortScience 28:519.

Whitaker, B.D. and W.R. Lusby. 1989. Steryl lipid content and composition in bell pepper fruit at three stages of ripening. J. Amer. Soc. Hort. Sci. 114:648-651. 